www.palgrave-journals.com/jors/

\title{
Erratum
}

\section{Cost allocation in the establishment of a collaborative transportation agreement - an application in the furniture industry}

J-F Audy, S D'Amours and L-M Rousseau

Journal of the Operational Research Society (2010) 61, 1559. doi:10.1057/jors.2010.139

Correction to: Journal of the Operational Research Society (2010). doi:10.1057/jors.2010.53

It has come to our notice that two errors were made in this paper.

On the ninth page of this paper, the conjunction 'and' was missing from the sentence that begins 'Consequently, this allows company A to evaluate further than the two regions...'; the correct version of this sentence is 'Consequently, this allows company A to evaluate further than the two regions and the periods of time of the study, the return on investment of any project, eg to renew handling or warehousing equipment'.

In the reference list, the reference for Kumar and van Dissel (1996) gave the incorrect initial of $U$ for author Kumar. The correct reference is: Kumar K and van Dissel HG (1996). Sustainable collaboration: Managing conflict and cooperation in interorganizational systems. MIS Quarterly 20(3): 279-300. 